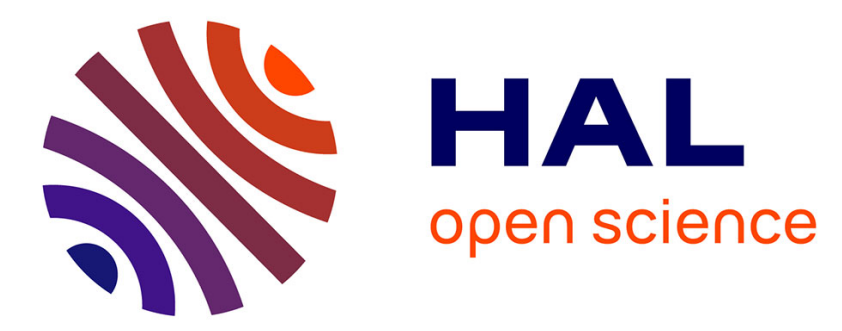

\title{
Synthesis of a double-stranded spiroborate helicate bearing stilbene units and its photoresponsive behaviour
}

Daisuke Taura, Heejun Min, Claudine Katan, Eiji Yashima

\section{To cite this version:}

Daisuke Taura, Heejun Min, Claudine Katan, Eiji Yashima. Synthesis of a double-stranded spiroborate helicate bearing stilbene units and its photoresponsive behaviour. New Journal of Chemistry, 2014, 39 (5), pp.3259-3269. 10.1039/C4NJ01669F . hal-01081618

HAL Id: hal-01081618

https://hal-univ-rennes1.archives-ouvertes.fr/hal-01081618

Submitted on 10 Nov 2014

HAL is a multi-disciplinary open access archive for the deposit and dissemination of scientific research documents, whether they are published or not. The documents may come from teaching and research institutions in France or abroad, or from public or private research centers.
L'archive ouverte pluridisciplinaire HAL, est destinée au dépôt et à la diffusion de documents scientifiques de niveau recherche, publiés ou non, émanant des établissements d'enseignement et de recherche français ou étrangers, des laboratoires publics ou privés.

$$
\text { Copyright }
$$




\title{
Synthesis of a double-stranded spiroborate helicate bearing stilbene units and its photoresponsive behaviour $\dagger$
}

\author{
Daisuke Taura, ${ }^{a}$ Heejun Min, ${ }^{a}$ Claudine Katan ${ }^{b}$ and Eiji Yashima*a \\ Received (in $X X X, X X X)$ Xth $X X X X X X X X X 20 X X$, Accepted Xth $X X X X X X X X X 20 X X$ \\ ${ }_{5}$ DOI: 10.1039/b000000x
}

\begin{abstract}
A novel spiroborate-based double-stranded helicate bearing photoresponsive cis-stilbene units in the middle (cis-3) was successfully synthesised from the corresponding cis-stilbene-bound tetraphenol strand in the presence of $\mathrm{NaBH}_{4}$, whereas the tetraphenol strands with a trans-stilbene or trans-azobenzene unit did not form such a double-stranded helicate. The ${ }^{1} \mathrm{H}$ NMR and NOESY experiments revealed that cis-3 10 adopted contracted $\left(c i s-\mathbf{3}_{\mathbf{C}}\right)$ and extended $\left(c i s-\mathbf{3}_{\mathbf{E}}\right)$ forms under equilibrium in $\mathrm{CD}_{3} \mathrm{CN}$ at $25{ }^{\circ} \mathrm{C}$. The contracted cis-3 $\mathbf{3}_{\mathrm{C}}$ that accommodated a $\mathrm{Na}^{+}$ion in the center showed an almost reversible extension and contraction motion by removal and addition of a $\mathrm{Na}^{+}$ion. The cis-to-trans photoisomerisation of the extended cis-3 $\mathbf{3}_{\mathbf{E}}$ with UV light $(295 \mathrm{~nm})$ further induced an extension of the helicate, producing a mixture of cis,trans $-\mathbf{3}_{\mathbf{E}}$ and trans- $\mathbf{3}_{\mathbf{E}}$ helicates at the photostationary state. However, trans-to-cis 15 photoisomerisation of the trans-mixtures using UV light $(360 \mathrm{~nm})$ was irreversible in this system and produced the photooxidated aldehyde species (trans-4), resulting from the photo-cleavage of the transstilbene moieties of the trans-3 $\mathbf{E}$.
\end{abstract}

\section{Introduction}

The design and synthesis of functional molecules and polymers 20 that exhibit a unidirectional molecular motion, such as rotary and elastic (extension and contraction) motions induced by external stimuli, ${ }^{1}$ in particular by irradiation of light have attracted a great deal of attention in the past two or three decades, ${ }^{2}$ because such photoresponsive molecular and polymeric systems can be applied ${ }_{25}$ for developing molecular motors, ${ }^{2 \mathrm{a}-2 \mathrm{~d}, 2 \mathrm{~g}, 3}$ artificial muscles, ${ }^{1 \mathrm{i}, \mathrm{lj}, 4}$ and molecular devices and materials. ${ }^{2 \mathrm{~d}-2 \mathrm{f}, 5}$

We previously reported a series of ortho-linked tetraphenol strands bearing a biphenol, ${ }^{6}$ biphenylene $(\mathbf{1}),{ }^{7}$ bipyridine, ${ }^{8}$ or bisporphyrin $^{9}$ unit in the middle that formed unique double30 stranded helicates bridged by two spiroborates in which one ${ }^{6,7}$ or two $\mathrm{Na}^{+}$cations ${ }^{8}$ were accommodated in the center except for a large bisporphyrin-linked spiroborate helicate. ${ }^{9}$ Conventional optical resolution of these helicates, such as diastereomeric salt formation or chiral high-performance liquid chromatography

35 (HPLC) separation, provided pairs of optically pure enantiomers being stable toward racemisation. Among the helicates prepared so far, the optically active biphenylene-linked spiroborate helicate

\footnotetext{
${ }^{a}$ Department of Molecular Design and Engineering, Graduate School of 40 Engineering, Nagoya University, Chikusa-ku, Nagoya 464-8603, Japan. Fax: +81-52-789-3185; Tel: +81-52-789-4495; E-mail: yashima@apchem.nagoya-u.ac.jp

${ }^{b}$ Institut des Sciences Chimiques de Rennes, UMR 6226 CNRS-Université de Rennes 1, France.

$45 \dagger$ Electronic Supplementary Information (ESI) available: Additional spectroscopic data. See DOI: 10.1039/b000000x/
}

(1) showed an intriguing ion-triggered reversible extension and contraction motion coupled with a unidirectional twisting motion upon release and binding of $\mathrm{Na}^{+}$ions (Scheme $1 \mathrm{~A}$ ) ${ }^{7 \mathrm{a}}$ the ${ }_{50}$ contracted helicate $\left(\mathbf{1}_{\mathbf{C}}\right)$ significantly extended through addition of [2.2.1]cryptand ([2.2.1]), resulting in the formation of extended helicate $\left(\mathbf{1}_{\mathbf{E}}\right)$ with a B-B distance of $13.0 \AA$ that is more than two-fold when compared with that of the contracted $\mathbf{1}_{\mathbf{C}}(6.0$ $\AA$ ). One might anticipate that if this unique spring-like motion 55 could be controlled by irradiation of light, this would contribute to developing feasible nanoscale mechanical devices. ${ }^{1 \mathrm{~g}, 2,5 \mathrm{e}}$

To this end, we have designed and synthesized three novel ortho-linked tetraphenol strands linked by photoresponsive cisand trans-stilbene ${ }^{4 \mathrm{~b}, 10}$ and trans-azobenzene ${ }^{10 \mathrm{~b}, 11}$ units in the 60 middle (Scheme 2) and investigated their double-stranded helicate formations stabilised by spiroborates with $\mathrm{NaBH}_{4}$. We found that only the cis-stilbene-containing tetraphenol strand yielded a desired double-stranded spiroborate helicate (cis-3), whereas the tetraphenol strands with a trans-stilbene or trans${ }_{65}$ azobenzene unit did not give such a helicate. We expected that the contracted helicate $c i s-\mathbf{3}_{\mathbf{C}}$ would undergo an extension (cis$\left.\mathbf{3}_{\mathbf{E}}\right)$ and contraction $\left(\right.$ cis $\left.-\mathbf{3}_{\mathbf{C}}\right)$ motion by the $\mathrm{Na}^{+}$ion release and binding (chemical stimulus) as well as by light irradiation (physical stimulus) through cis-to-trans photoisomerisation of the 70 stilbene units, thus producing cis-3 $\mathbf{3}_{\mathbf{E}}$ and more extended trans $-\mathbf{3}_{\mathbf{E}}$, respectively (Scheme 1B). Although this cis-trans photoisomerisation was irreversible because of the photocleavage of the trans-stilbene moieties under irradiation of light, to the best of our knowledge, wholly-artificial double helices 75 showing a light-triggered spring-like motion are hitherto unknown. ${ }^{4 \mathrm{~d}, 12,13}$ 
(A)

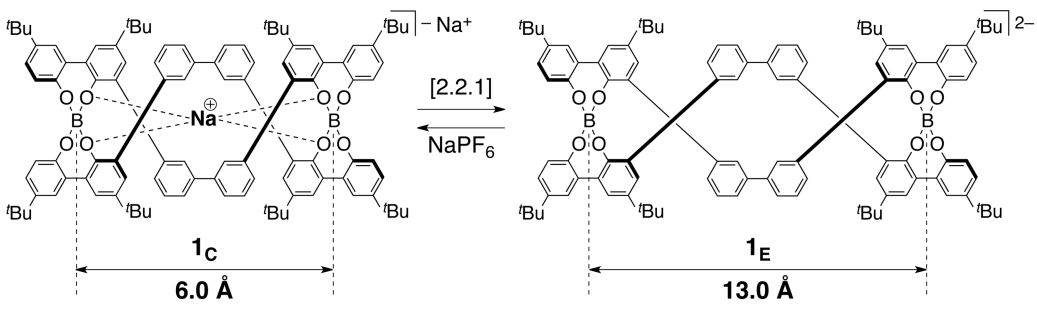

(B)

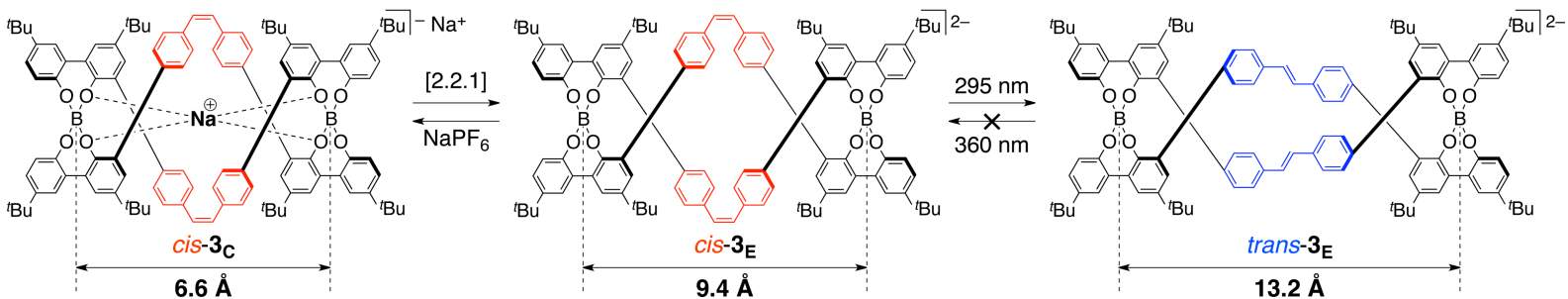

Scheme 1 Extension (E) and contraction (C) motions of spiroborate-based double-stranded helicates bearing biphenyl units (1) (A) and stilbene units (3)

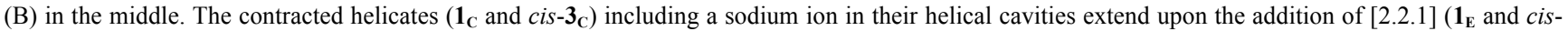
$\mathbf{3}_{\mathrm{E}}$ ). Further addition of $\mathrm{NaPF}_{6}$ causes the formation of contracted forms. The cis- $\mathbf{3}_{\mathrm{E}}$ is further extended upon cis-to-trans photoisomerisation.
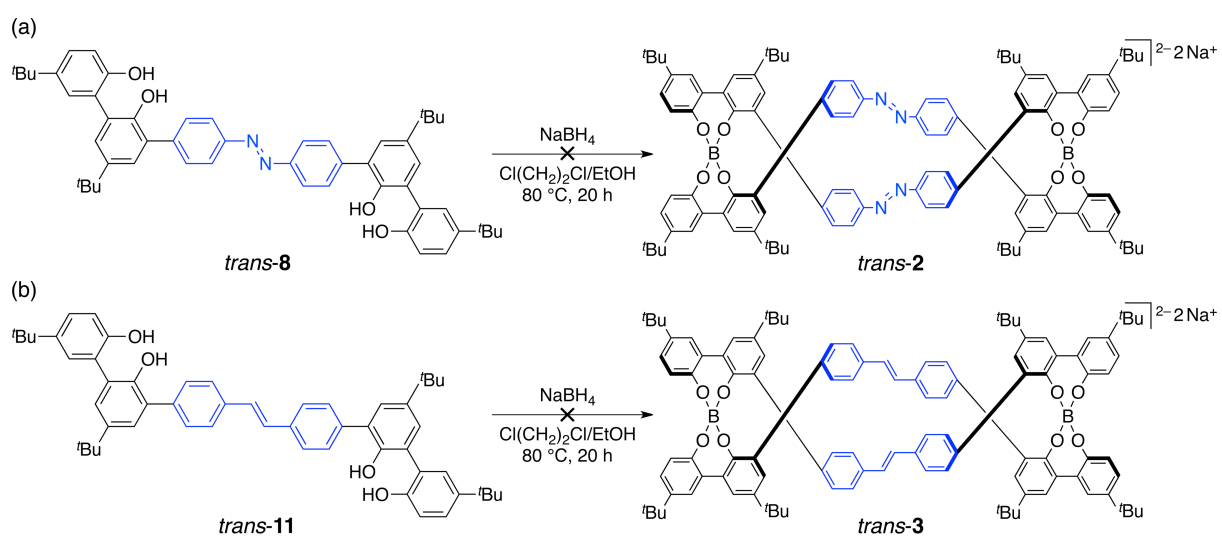

(c)
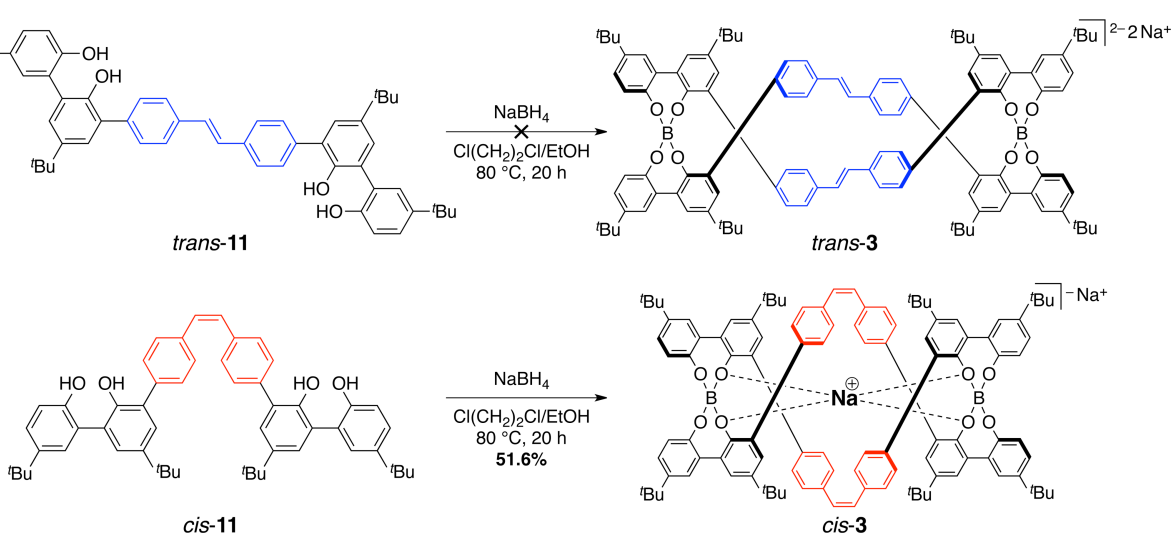

Scheme 2 Synthesis of spiroborate-based helicates bearing trans-azobenzene (trans-2) (a), trans-stilbene (trans-3) (b), and cis-stilbene (cis-3) (c) units in the middle.

\section{${ }_{10}$ Results and discussion}

Synthesis of tetraphenol strands linked by photoresponsive units and the corresponding spiroborate helicates

The trans-azobenzene-containing tetraphenol (trans-8) was synthesised by Suzuki-Miyaura coupling of a boronic acid (5) 15 with trans-4,4'-diiodoazobenzene (trans-6), subsequently followed by deprotection of the methoxy groups using $\mathrm{BBr}_{3}$ according to a previously reported $\operatorname{method}^{6-8}$ (Scheme $\mathrm{S} 1$ in ESI $\dagger$ ). The trans- and cis-stilbene-containing tetraphenols (trans11 and cis-11, respectively) were also synthesised in a similar 20 way by Suzuki-Miyaura coupling of a boronic acid ester $(9)^{9}$ with the corresponding trans- and cis-4,4'-diiodostilbenes (trans-10 and cis-10, respectively) (Scheme S2 in ESI†).

The obtained tetraphenol strands were then allowed to react with an equimolar amount of $\mathrm{NaBH}_{4}$ in 1,2-dichloroethane and 25 ethanol $(5 / 1, \mathrm{v} / \mathrm{v})$ at $80^{\circ} \mathrm{C}$ for $20 \mathrm{~h}$ under similar conditions used for the synthesis of the spiroborate helicates reported previously ${ }^{6-}$ ${ }^{8}$ (Scheme 2). However, the products from trans-8 and trans-11 were complicated based on their ${ }^{1} \mathrm{H}$ NMR spectra, and the electrospray ionisation (ESI) mass spectra in the negative mode 30 indicated the formation of dimers and trimers bridged by one and two spiroborates, respectively, along with unreacted strands (Scheme 2a, b and Figs. S1 and S2 in ESI $\dagger$ ), probably because the planar trans-azobenzene and trans-stilbene units hamper such a twisted spiroborate formation due to steric effects.

35 On the other hand, the cis-stilbene strand (cis-11) favourably reacted with $\mathrm{NaBH}_{4}$, giving the corresponding helicate (cis-3) in $51.6 \%$ yield under the same condition (Scheme 2c) as supported by the ESI mass spectrum, which showed signals due to the 
(A)

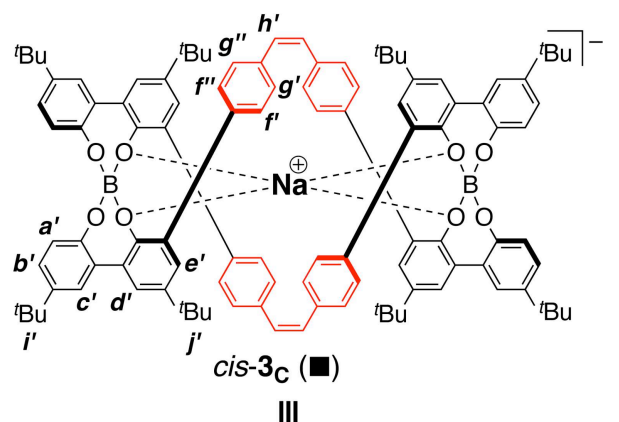

III

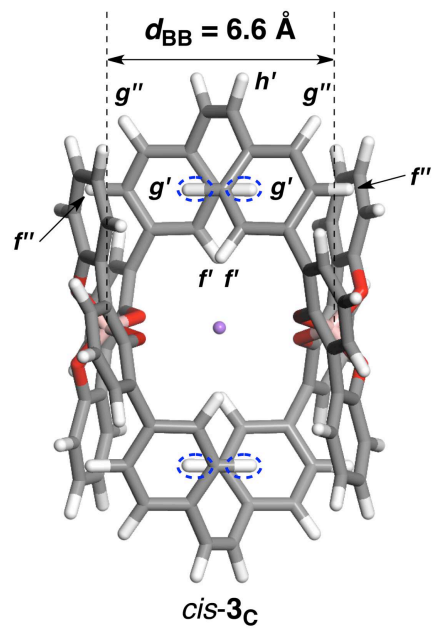

$\mathrm{Na}^{+}$

$\stackrel{\mathrm{NaPF}_{6}}{\longrightarrow}$

(B)

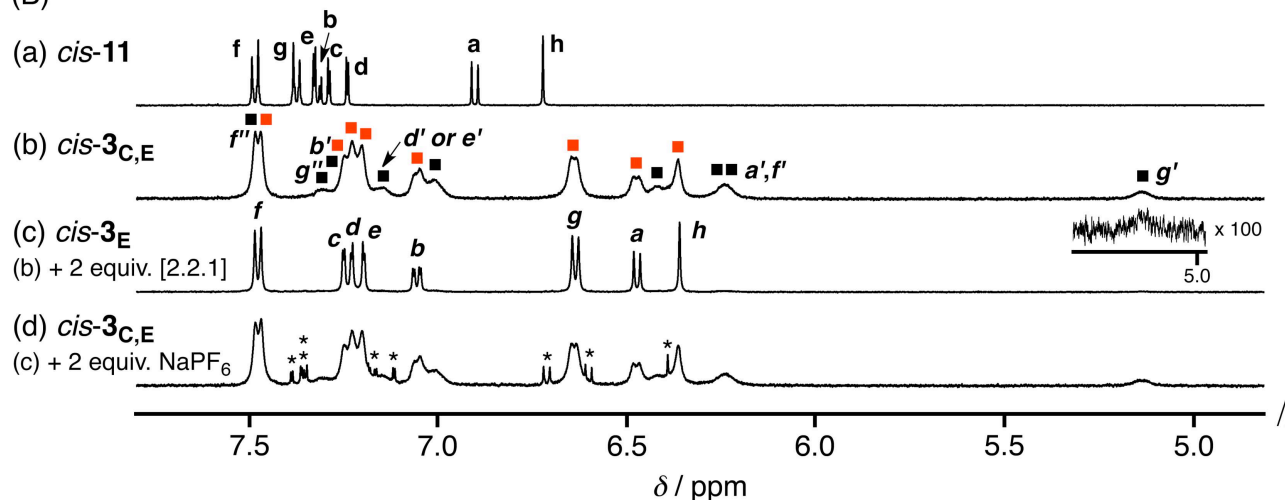

$\delta / \mathrm{ppm}$

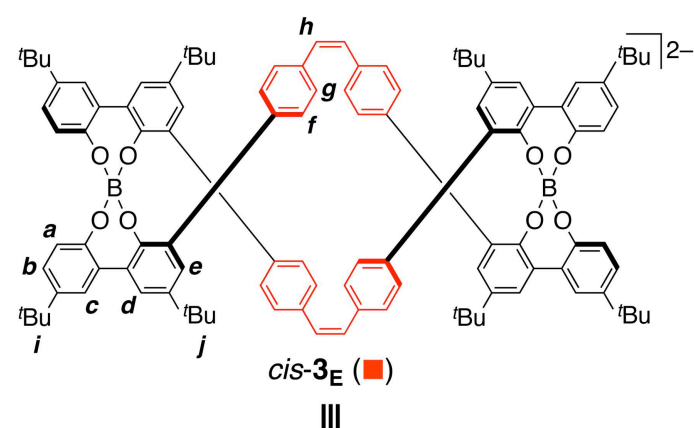

III

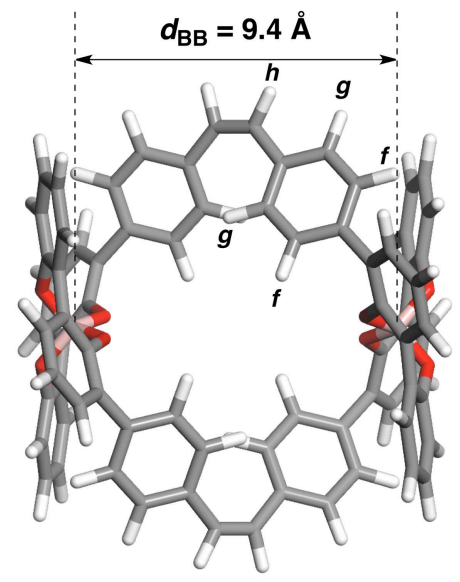

cis-3 $\mathbf{3}_{\mathrm{E}}$

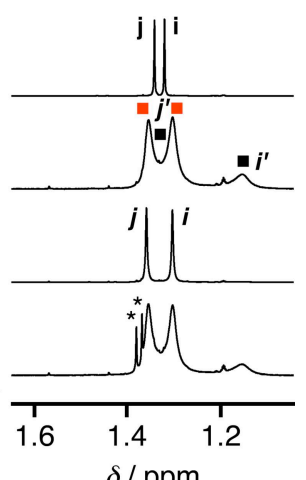

Fig. 1 (A) Optimised structures of left-handed helical $c i s-\mathbf{3}_{\mathrm{C}}$ (monoanion) and $c i s-\mathbf{3}_{\mathbf{E}}$ (dianion) calculated by Hartree-Fock method (6-31G*, $\left.\mathrm{CH}{ }_{3} \mathrm{CN}\right)$, in which all the ${ }^{t} \mathrm{Bu}$ groups were substituted with hydrogen atoms for simplifying the calculations. (B) ${ }^{1} \mathrm{H} \mathrm{NMR} \mathrm{spectra}\left(500 \mathrm{MHz}, \mathrm{CD}{ }_{3} \mathrm{CN}, 25{ }^{\circ} \mathrm{C}\right)$ of cis-11 $(0.65 \mathrm{mM})(\mathrm{a})$, cis-3 $(0.31 \mathrm{mM})(\mathrm{b}),(\mathrm{b})+2$ equiv. [2.2.1] (c), and (c) +2 equiv. $\mathrm{NaPF}_{6}(\mathrm{~d}) . \mathrm{B}$ and B denote the signals for the contracted (cis-3 $)$ and 5 extended $\left(\right.$ cis $\left.-\mathbf{3}_{\mathrm{E}}\right)$ helicates, respectively. The peak assignments were done on the basis of gCOSY and NOESY spectra (Figs. S5-S8 in ESI $\left.\dagger\right)$. ${ }^{*}$ denotes the signals tentatively assigned to the meso-cis-3 $\mathbf{E}_{\mathrm{E}}$ (see the text and Figs. S9 and S10 in ESI $\dagger$ ).

monovalent $\left(\right.$ cis $\left.^{-} \mathbf{3}^{-}\right)$and divalent $\left(\right.$cis $\left.^{-3^{2-}}\right)$ anions at $m / z=1581.75$ and 779.36, respectively (Fig. S3 in ESI†).

\section{Extension and contraction motion of $c$ is-3}

${ }_{10}$ Figs. 1B (a and b) show the ${ }^{1} \mathrm{H}$ NMR spectra of cis-11 and cis-3, respectively, measured in $\mathrm{CD}_{3} \mathrm{CN}$ at $25^{\circ} \mathrm{C}$. Interestingly, most of the proton resonances for cis-3 appeared as two sets of nonequivalent broadened signals after spiroborate helicate formation (B and B, b in Fig. 1B); such nonequivalent proton 15 resonances have not been observed for the other spiroborate helicates prepared so far. $^{6-9}$ In order to assign these signals, 2 equiv. of [2.2.1] were added to a solution of cis-3. As shown in c in Fig. 1B, the broad signals became sharper ones, while maintaining their chemical shifts (B) along with significant
20 decrease in the signals marked by B in c in Fig. 1B. As reported previously, the $\mathrm{Na}^{+}$ion weakly bound in the contracted helicate $\left(\mathbf{1}_{\mathbf{C}}\right)$ could be released quantitatively in the presence of [2.2.1], resulting in the formation of the extended helicate $\left(\mathbf{1}_{\mathbf{E}}\right)$ (Scheme 1A). ${ }^{7 a}$ Based on these observations, the two sets of nonequivalent 25 signals (B and B, b in Fig. 1B) could be reasonably assigned to those of the contracted $\left(\right.$ cis $\left.-\mathbf{3}_{\mathbf{C}}\right)$ and extended ( $\left.c i s-\mathbf{3}_{\mathbf{E}}\right)$ forms, respectively, which indicates that the $\mathrm{Na}^{+}$ion binding and release rates, in other words, the corresponding contracted and extended motions of cis-3 are slow in $\mathrm{CD}_{3} \mathrm{CN}$ on the ${ }^{1} \mathrm{H}$ NMR time scale, 30 giving separated signals under equilibrium (b in Fig. 1B), from which the ratio of $c i s-\mathbf{3}_{\mathbf{C}}$ to $c i s-\mathbf{3}_{\mathbf{E}}$ and its equilibrium constant $(K)$ were estimated to be $30: 70$ and $2 \times 10^{3} \mathrm{M}^{-1}$, respectively. In the presence of [2.2.1] (2 equiv.), the ratio of $c i s-\mathbf{3}_{\mathbf{C}}$ to $c i s-\mathbf{3}_{\mathbf{E}}$ changed 
Table 1 Results of the photoisomerisation of cis-11 and cis-3 in $\mathrm{CD}_{3} \mathrm{CN}$ upon irradiation of UV light at 295 and subsequently at $360 \mathrm{~nm}$

\begin{tabular}{|c|c|c|c|c|c|c|}
\hline & $11^{a, b}$ & & & $\mathbf{3}^{a, c}$ & & \\
\hline & cis-11 : trans-11 & $\begin{array}{c}c i s-3 / \\
\%\end{array}$ & cis,trans $-\mathbf{3}_{\mathbf{E}} / \%$ & trans-3 $\mathbf{3}_{\mathbf{E}} / \%$ & trans-4 / \% & cis : trans $^{d}$ \\
\hline Before irradiation & $99: 1$ & 97 & 3 & 0 & 0 & $98.5: 1.5$ \\
\hline $\begin{array}{c}\text { After irradiation with } 295 \\
\text { nm light } \\
\text { (cis-to-trans })\end{array}$ & $8: 92$ & 21 & 39 & 38 & 2 & $40.5: 58.5$ \\
\hline $\begin{array}{c}\text { After irradiation with } 360 \\
\text { nm light } \\
(\text { trans-to-cis })\end{array}$ & $42: 56^{e}$ & 24 & 43 & 20 & 13 & $45.5: 48.0$ \\
\hline
\end{tabular}

${ }^{a}$ Product ratios were estimated by ${ }^{1} \mathrm{H}$ NMR analyses. ${ }^{b} 0.65 \mathrm{mM}$ at $25{ }^{\circ} \mathrm{C}$ under air (see Figs. S1 1 and S12 in ESI $\dagger$ ). ${ }^{c} 0.25 \mathrm{mM}$ cis-3 in the presence of 2 equiv. [2.2.1] at $25{ }^{\circ} \mathrm{C}$ under argon (see Fig. 3 and Fig. S15 in ESI†). ${ }^{d}$ Overall cis and trans ratio of the stilbene units of 3 and $4 .{ }^{e}$ A trace amount of oxidised aldehydes (ca. $2 \%$ ) was produced during the photoisomerisation (see Fig. S11b in ESI $\uparrow$ ).

to be approximately $10: 90$ (c in Fig. 1B). The further addition of [2.2.1] (3 equiv.) brought about the complete shift of the equilibrium to the extended helicate formation $\left(\right.$ cis- $\left.\mathbf{3}_{\mathbf{E}}\right)$.

According to this assignment, the upfield shifts of some 10 aromatic protons for $c i s-\mathbf{3}$, in particular those for cis-3 $\mathbf{3}_{\mathbf{C}}$ (b in Fig. 1B), were explained by the shielding effect of the benzene rings of the other strand as observed in the other spiroborate helicates. ${ }^{6-}$ 9 The upfield shift of the stilbene protons (g') was more significant. The calculated structures of $c i s-\mathbf{3}_{\mathbf{C}}$ and $c i s-\mathbf{3}_{\mathbf{E}}$ in ${ }_{15} \mathrm{CH}_{3} \mathrm{CN}$ by using the Hartree-Fock method (HF, 6-31G*) support the upfield shifts of the stilbene protons ( $\left.\mathrm{g}^{\prime}\right)$ of $c i s-\mathbf{3}_{\mathbf{C}}$, which are favourably positioned above the benzene rings of the twisted stilbene residues into one direction (Fig. 1A). The energy difference $\left(\Delta G_{\text {Cal }}\right)$ between the calculated structures in ${ }_{20} \mathrm{CH}_{3} \mathrm{CN}$ revealed that the cis-3 $\mathbf{3}_{\mathbf{E}}$ is $2 \mathrm{kcal} \mathrm{mol}^{-1}$ more stable than the cis-3 $\mathbf{3}_{\mathrm{C}}$ (Fig. 1A), which is consistent with the major species (cis-3 $\mathbf{3}_{\mathbf{E}}$ ) observed by the ${ }^{1} \mathrm{H}$ NMR spectrum of cis-3 in $\mathrm{CD}_{3} \mathrm{CN}$ at $298 \mathrm{~K}$ at equilibrium (b in Fig. 1B).

The equilibrium between $c i s-\mathbf{3}_{\mathbf{C}}$ and $c i s-\mathbf{3}_{\mathbf{E}}$ was also 25 unambiguously confirmed by the concentration-dependent ${ }^{1} \mathrm{H}$ NMR and 2D NOESY (2D exchange spectroscopy (EXSY)) spectra of cis-3 in the absence and presence of [2.2.1] (2 equiv.), respectively. ${ }^{14}$ The intensities of the signals (B) derived from cis$\mathbf{3}_{\mathbf{C}}$ gradually decreased with the decrease in the concentration of 30 cis-3 $(0.31-0.080 \mathrm{mM})$, whereas those of the signals (B) due to cis $-\mathbf{3}_{\mathbf{E}}$ relatively increased and the signals became sharper without any changes in their chemical shifts (Fig. S4 in ESI $\dagger$ ), from which the $K$ value was also estimated to be $2 \times 10^{3} \mathrm{M}^{-1}$, indicating that the equilibrium involves the sodium ion release 35 and binding. In addition, the 2D NOESY (EXSY) spectrum of cis-3 with 2 equiv. of [2.2.1] showed clear positive exchange cross-peaks between the two species, contracted $c i s-\mathbf{3}_{\mathrm{C}}(\mathrm{B})$ and extended $c i s-\mathbf{3}_{\mathbf{E}}$ (B) forms as well as negative intrastrand NOE cross-peaks for cis $^{-3_{\mathbf{E}}}$ (Figs. S6-S8 in ESI $\dagger$ ). Although interstrand ${ }_{40} \mathrm{NOE}$ cross-peaks were not observed for $\mathrm{cis}-\mathbf{3}_{\mathbf{E}}$, a similar tendency was reported for the other extended spiroborate helicates. ${ }^{7 \mathrm{a}}$

The subsequent addition of $\mathrm{NaPF}_{6}$ to the solution of $c i s-\mathbf{3}_{\mathbf{E}}$ in the presence of 2 equiv. of [2.2.1] (d in Fig. 1B) regenerated the original helicates as a mixture of $c i s-\mathbf{3}_{\mathbf{C}}$ and $c i s-\mathbf{3}_{\mathbf{E}}$, while new ${ }_{45}$ sharp signals different from those of the ligand cis-11 and the helicates $\left(c i s-\mathbf{3}_{\mathbf{C}}\right.$ and $\left.c i s-\mathbf{3}_{\mathbf{E}}\right)$ appeared in the aromatic and $t$-Bu proton resonance regions; the content of the new species was ca. $6 \%$ (d in Fig. 1B). We found that the identical new species also formed when a $\mathrm{CD}_{3} \mathrm{CN}$ solution of $c i s-\mathbf{3}$ was allowed to stand for ${ }_{95}$ a long time (Fig. S9A in ESI $\uparrow$ ); its ESI mass spectrum (Fig. S10 in ESI $\dagger$ ) was identical to that measured just after dissolving cis-3 in $\mathrm{CH}_{3} \mathrm{CN}$ (Fig. $\mathrm{S} 3$ in $\mathrm{ESI} \dagger$ ). These results together with the COSY spectrum of a $\mathrm{CD}_{3} \mathrm{CN}$ solution of cis-3 after standing for ca. $36 \mathrm{~h}$ (Fig. S9B in ESI $\dagger$ ) suggest that the new species is a ${ }_{55}$ structural isomer of the racemo-helicates $\left(c i s-\mathbf{3}_{\mathbf{C}}\right.$ and $\left.c i s-\mathbf{3}_{\mathbf{E}}\right)$ and is most likely a double-stranded meso-helicate with an extended structure (meso-cis- $\mathbf{3}_{\mathbf{E}}$ ) that will be generated from the racemohelicates in solution and reached an equilibrium within a few days. Indeed, calculations predict that meso-cis- $\mathbf{3}_{\mathbf{E}}$ is $2.7 \mathrm{kcal}$ ${ }_{60} \mathrm{~mol}^{-1}$ more stable than $c i s-\mathbf{3}_{\mathbf{E}}$ (Table S1 in ESI $\dagger$ ). Although the mechanism for the present racemo-to-meso-cis-3 isomerisation, which requires the breaking and reformation process of the spiroborate groups, remains unknown, these results revealed that the racemo-cis-3 exists as a mixture of the interconvertible ${ }_{65}$ contracted $\left(c i s-\mathbf{3}_{\mathbf{C}}\right)$ and extended $\left(\right.$ cis $\left.-\mathbf{3}_{\mathbf{E}}\right)$ forms in solution and that the ion-triggered extension and contraction motion mostly proceeds reversibly; however, the present system seems to be more complicated than before, and involves the other chemical equilibrium, i.e., racemo-to-meso-cis-3 isomerisation. 70 Apparently, a further study is necessary to unambiguously elucidate the structure of the meso-cis- $\mathbf{3}_{\mathbf{E}}$ by single-crystal X-ray analysis and the mechanism of this unexpected isomerisation.

\section{Photoisomerisation of cis-11}

Cis/trans photoisomerisation of the single strand cis-11 was first 75 investigated by ${ }^{1} \mathrm{H}$ NMR and absorption spectroscopies in $\mathrm{CD}_{3} \mathrm{CN}$ (Figs. S11-S12 and S13-S14, respectively in ESI $\dagger$ ). Upon irradiation of UV light at $295 \mathrm{~nm}$, the intensities of the cis-11 protons decreased with time, while the new peaks due to trans-11 appeared with a gradual increase in their intensities and the 80 cis/trans ratio reached a constant value $(8: 92)$ after irradiation for $120 \mathrm{~min}$ as estimated from the integral ratio of the cis- and trans-stilbene protons $\left(\mathrm{f}_{\mathrm{c}}\right.$ and $\mathrm{g}_{\mathrm{t}}$ ) (Table 1 and Fig. S11a in ESI $\dagger$ ). Subsequent irradiation with UV light at $360 \mathrm{~nm}$, which induces the trans-to-cis isomerisation, produced a mixture of cis- and 85 trans-11 (Fig. S11b in ESI $\dagger$ ); its ratio changed with time and reached an almost constant value $(42: 56)$ at the photostationary state after $120 \mathrm{~min}$ irradiation (Table 1 and Fig. S12 in ESI $\dagger$ ), indicating that the trans-to-cis photoisomerisation did not take place efficiently as reported for typical stilbene derivatives. ${ }^{15}$

90 The changes in the absorption spectra of cis-11 in a dilute $\mathrm{CD}_{3} \mathrm{CN}$ solution during the course of the cis-to-trans followed by the trans-to-cis photoisomerisations were also measured (Fig. S13 in ESI $\uparrow$ ). An absorption peak at $335 \mathrm{~nm}$ due to the formation of trans-11 gradually increased with time accompanied with a 


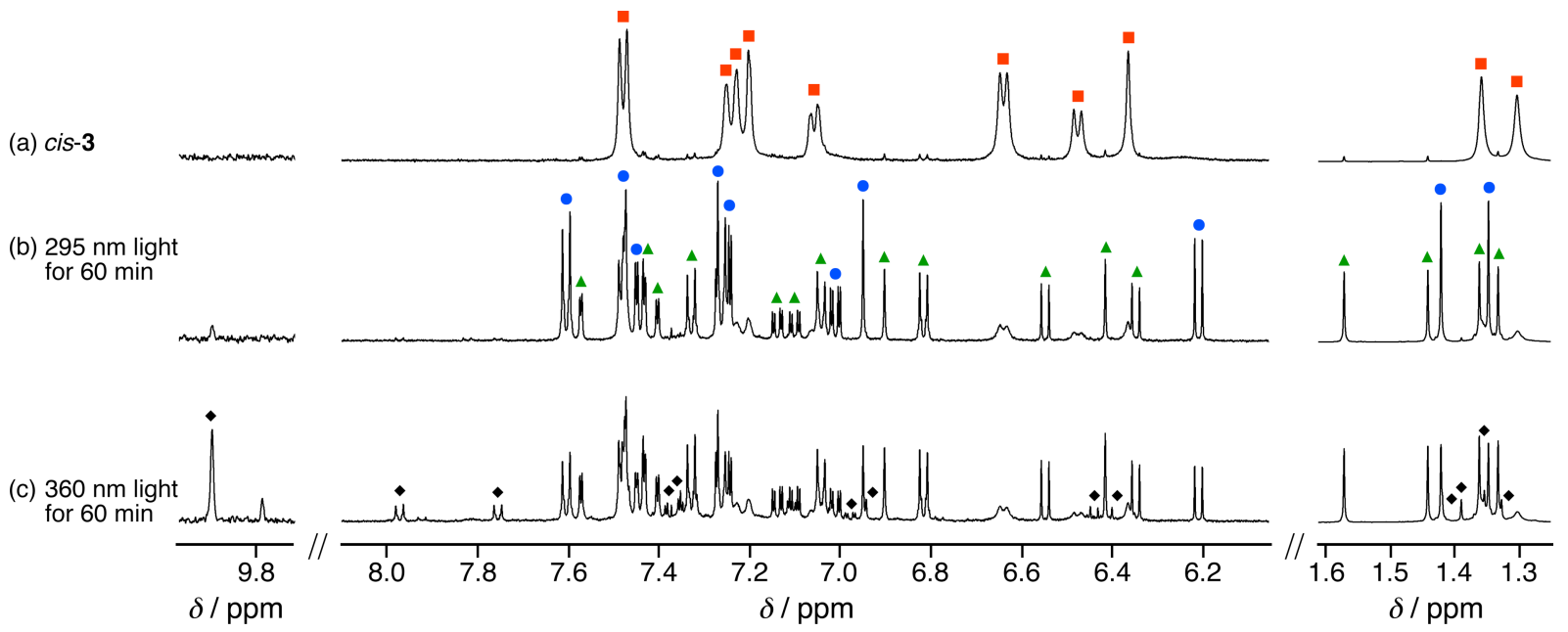

Fig. $2{ }^{1} \mathrm{H}$ NMR spectral changes of cis-3 $\left(500 \mathrm{MHz}, \mathrm{CD}_{3} \mathrm{CN}, 25^{\circ} \mathrm{C}, 0.25 \mathrm{mM}\right)$ in the presence of 2 equiv. [2.2.1] before (a) and after irradiation of $\mathrm{UV}$ light at $295 \mathrm{~nm}$ for $60 \mathrm{~min}$ (b), followed by irradiation of UV light at $360 \mathrm{~nm}$ for $60 \mathrm{~min}$ under argon (c) (see Fig. S15 in ESI $\dagger$ ). B, H, J, and F denote the 5 signals for cis- $\mathbf{3}_{\mathrm{E}}$, cis, trans $-\mathbf{3}_{\mathrm{E}}$, trans $-\mathbf{3}_{\mathrm{E}}$, and trans $-\mathbf{4}$, respectively. The peak assignments were done on the basis of the ESI-MS spectrum of the mixture (Fig. S16 in ESI $\dagger$ ) and gCOSY and NOESY spectra (Figs. S17-S19 in ESI $\dagger$ ).
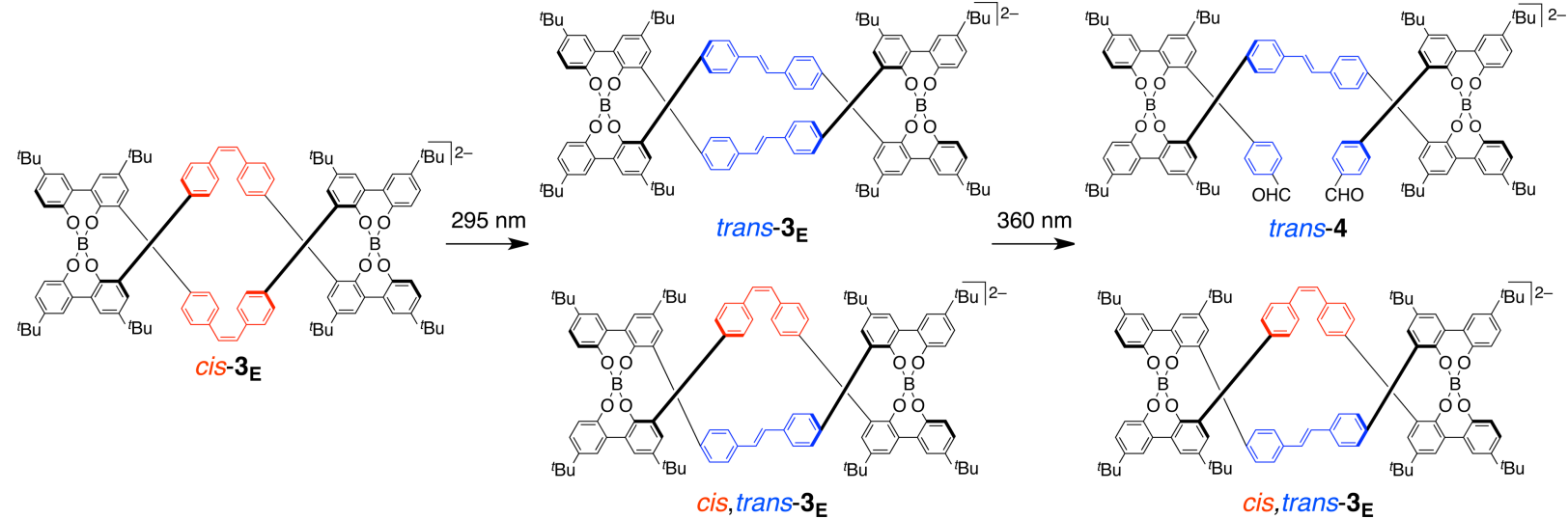

Scheme 3 Photoisomerisation of cis- and trans-stilbene helicates.

10 clear isosbestic point at $298 \mathrm{~nm}$ upon irradiation of UV light at $295 \mathrm{~nm}$, affording the trans-11 in 94\% yield. Further irradiation with UV light at $360 \mathrm{~nm}$ gave a mixture of cis- and trans-11 (43: 57) at the photostationary state (Fig. S13b and c in ESI $\uparrow$ ); the cis/trans ratio was estimated by using a calibration curve 15 obtained from the plots for the absorption intensity ratio at 335 and $298 \mathrm{~nm}$ as a function of the trans-11 content estimated from the ${ }^{1} \mathrm{H}$ NMR analyses. The results were fully consistent with those obtained from the ${ }^{1} \mathrm{H}$ NMR analyses, although a trace amount of a photooxidised product (aldehydes) (ca. 2\%) was 20 produced upon irradiation of UV light at $360 \mathrm{~nm}$ under air as shown in Fig. S11 (ESI $\dagger$ ). As anticipated, the fluorescence intensity of $\mathbf{1 1}$ significantly increased during the cis-to-trans photoisomerisation (Fig. S14b in ESI $\dagger$ ).

\section{Photoisomerisation of cis-3}

${ }_{25}$ With all the above photoisomerisation results of cis-11 in mind, we then investigated the photoisomerisation behaviour of the double-stranded helicate cis-3 composed of two cis-11 strands with ${ }^{1} \mathrm{H}$ NMR and absorption spectroscopies in a manner similar to that for cis-11. Fig. 2 shows the ${ }^{1} \mathrm{H}$ NMR spectral changes of 30 cis-3 in $\mathrm{CD}_{3} \mathrm{CN}$ in the presence of 2 equiv. of [2.2.1] before and

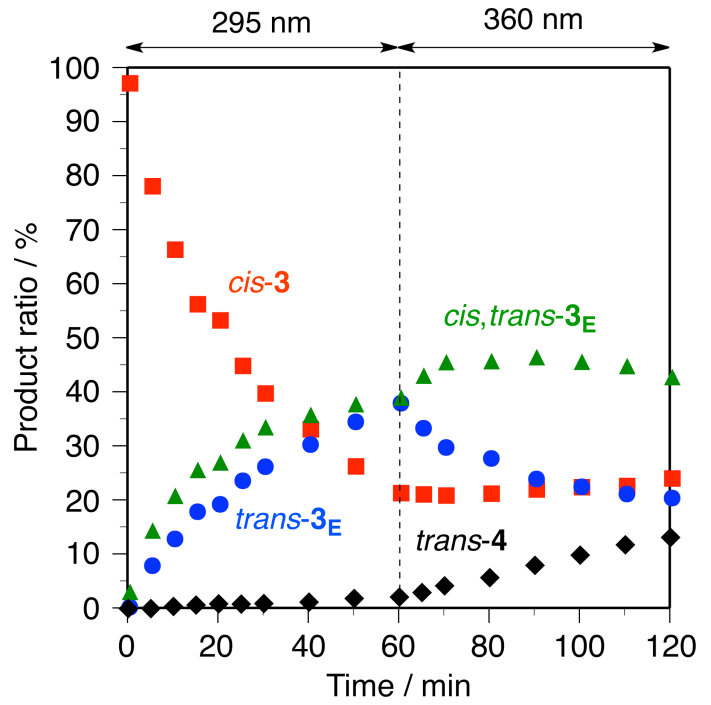

Fig. 3 Time-dependent changes in the product ratio during the photoisomerisation of cis-3 $(0.25 \mathrm{mM})$ in the presence of 2 equiv. [2.2.1] upon irradiation of UV light at $295 \mathrm{~nm}$, followed by irradiation of UV 35 light at $360 \mathrm{~nm}$ under argon (see Fig. S15 in ESI†). 

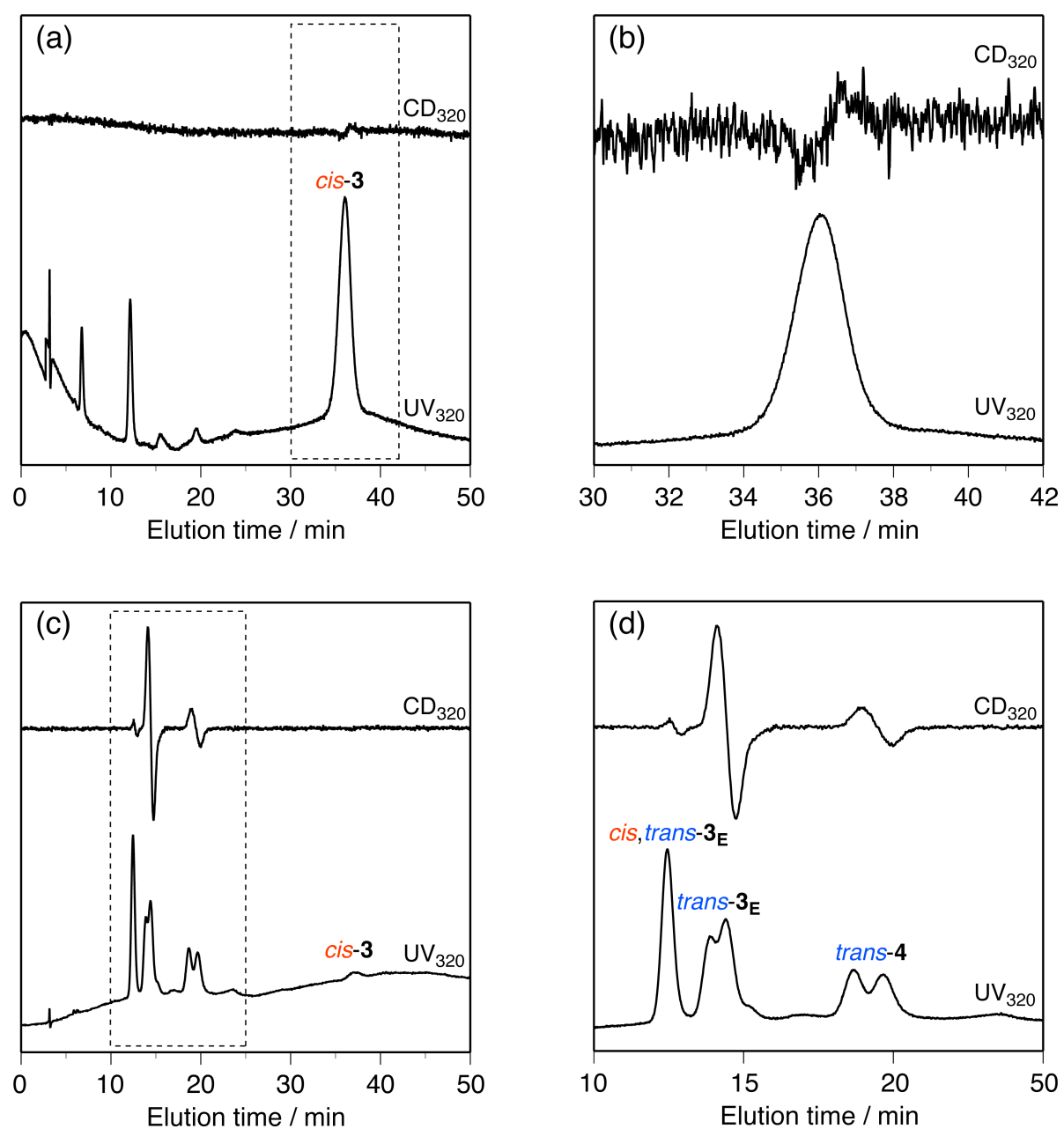

Fig. 4 HPLC chromatograms for the resolution of cis-3 in $\mathrm{CH}_{3} \mathrm{CN}$ (a) and cis-3 $\mathbf{3}_{\mathbf{E}}$ in the presence of 7 equiv. [2.2.1] in $\mathrm{CD}_{3} \mathrm{CN}$ after irradiation of $\mathrm{UV}$ light at $295 \mathrm{~nm}$ for $90 \mathrm{~min}$ under air (c) (see Fig. S21b in ESI $\dagger$ ). Magnified chromatograms corresponding to the areas indicated by the squares in (a) and (c) are shown in (b) and (d), respectively. HPLC conditions: column, Chiralpak IB (Daicel, 0.46 (i.d.) $\times 25 \mathrm{~cm}$ ); eluent: hexane/CHCl 3 (6:4, v/v) containing 0.5 $5 \mathrm{mg} / \mathrm{mL}$ tetrabutylammonium bromide (TBAB); flow rate, $1.0 \mathrm{~mL} \mathrm{~min}^{-1}$; column temperature, $25{ }^{\circ} \mathrm{C}$. The peak assignments were performed by fractionation of each peak, followed by measurements of the ${ }^{1} \mathrm{H}$ NMR spectra. We note that photoirradiation of cis $-\mathbf{3}_{\mathbf{E}}$ in air produced a larger amount of the photooxidised trans -4 .

after irradiation of UV light at $295 \mathrm{~nm}$ followed by $360 \mathrm{~nm}$ for 60 min each (for more detailed time-dependent ${ }^{1} \mathrm{H}$ NMR spectral

10 changes and the product ratio changes, see Fig. S15 in ESI $\dagger$ and Fig. 3, respectively).

In sharp contrast to cis-11, the ${ }^{1} \mathrm{H}$ NMR spectrum of cis-3 became quite complicated after irradiation of UV light at $295 \mathrm{~nm}$ for $60 \mathrm{~min}$ (Fig. 2b) because of newly generated cis,trans $-\mathbf{3}_{\mathbf{E}}$ and

15 trans $-\mathbf{3}_{\mathbf{E}}$ as well as the unreacted cis-3 $\mathbf{3}_{\mathbf{E}}$ (Scheme 3 ), suggesting that the cis-to-trans isomerisation in this system was less efficient presumably because of the highly strained, covalently-bonded spiroborated duplex structure (Fig. 1A); the product ratio estimated by its ${ }^{1} \mathrm{H}$ NMR spectrum (Fig. 2b) was cis,trans $-\mathbf{3}_{\mathbf{E}}$ $20(39 \%)$ and trans- $\mathbf{3}_{\mathbf{E}}(38 \%)$ along with a small amount of trans-4 (2\%) (Table 1, see below). However, it should be emphasised that the trans $-3_{\mathbf{E}}$, which was not directly synthesised by the reaction of trans-11 with $\mathrm{NaBH}_{4}$ under the conditions used for the synthesis of spiroborate helicates ${ }^{6-8,16}$ (Scheme 2), was 25 successfully produced via cis-to-trans photoisomerisation of the corresponding cis-3. Subsequent irradiation of UV light at 360 $\mathrm{nm}$ further produced a new set of proton resonances with a characteristic singlet at $9.84 \mathrm{ppm}$ (Fig. 2c), which could be derived from an aldehyde species (trans-4) most likely generated 30 by photooxidation of trans $-\mathbf{3}_{\mathbf{E}}$ in the presence of trace amounts of oxygen. ${ }^{17}$ The dialdehyde (trans-4) formation that was evidenced by the negative ESI-mass spectrum (Fig. S16B in ESI $\dagger$ ) unfortunately caused the irreversible trans-cis photoisomerisation of this system, and its content increased with time (Fig. S15 in 35 ESI $\uparrow$ and Table 1).

The photo-induced cis/trans isomerisation of cis-3 $\mathbf{3}_{\mathbf{E}}$ was also investigated by absorption spectroscopy. Similar time-dependent absorption spectral changes of cis-3 $\mathbf{3}_{\mathbf{E}}$ in a dilute $\mathrm{CD}_{3} \mathrm{CN}$ solution containing 3 equiv. of [2.2.1] were observed during the course of 40 the cis-to-trans and trans-to-cis photoisomerisations, but the changes were not significant as compared to those of cis-11 because of inefficient cis-to-trans isomerisation and oxidation that took place during the trans-to-cis photoisomerisation, giving the oxidized trans-4 (Fig. S20a, b in ESI $\dagger$ ). The fluorescence ${ }_{45}$ intensity of $c i s-\mathbf{3}_{\mathbf{E}}$ was also enhanced upon irradiation of UV light $(295 \mathrm{~nm})$, resulting in the formation of a mixture of cis,trans $-\mathbf{3}_{\mathbf{E}}$, trans $-\mathbf{3}_{\mathbf{E}}$, and trans $-\mathbf{4}$ (Fig. S20c, d in ESI $\dagger$ ). 


\section{Optical resolution of helicates}

As mentioned above, the cis-3 just after preparation undergoes the ion-triggered extension and contraction motion in acetonitrile, which further changes its structure to a new species in acetonitrile 5 under equilibrium. We tentatively assigned the $c i s-\mathbf{3}$ and the new species as racemo- and meso-cis-3 $\mathbf{3}_{\mathbf{E}}$ helicates, respectively, on the basis of their NMR spectra. Obviously, the racemo-cis-3 helicate is chiral, whereas the meso-cis- $\mathbf{3}_{\mathbf{E}}$ helicate is achiral, and in order to confirm these structural assignments, we investigated if the ${ }_{10}$ chiral cis-3 could be resolved into enantiomers by HPLC using a chiral column (Chiralpak IB, Daicel).

Fig. 4a shows the chromatogram of the resolution of cis-3, showing a single peak detected by UV, although the circular dichroism (CD)-detected chromatogram indicated a partial 15 separation with negative and positive CDs; their CD intensities were too weak to evidence the enantioseparation (Fig. 4b). Next, a $\mathrm{CH}_{3} \mathrm{CN}$ solution of a mixture of cis,trans $-\mathbf{3}_{\mathbf{E}}$, trans $-\mathbf{3}_{\mathbf{E}}$, and trans $\mathbf{4}$ prepared from cis- $\mathbf{3}_{\mathbf{E}}$ through the photoisomerisation under air was injected into the chiral HPLC system (Fig. S21 in ${ }_{20}$ ESI $\dagger$ ). As shown in Fig. $4 d$, the trans-3 $\mathbf{3}_{\mathbf{E}}$ and trans $\mathbf{4}$ were not completely but rather were partially separated into a pair of enantiomers with the first positive and second negative CD signs. Importantly, the trans $-\mathbf{3}_{\mathbf{E}}$ and trans $\mathbf{-} \mathbf{4}$ were converted from cis $-\mathbf{3}_{\mathbf{E}}$ via photoisomerisation without any breaking and reformation ${ }_{25}$ process of the spiroborate groups, leading to the conclusion that the cis-3 is a racemo-helicate with a double-stranded spiroborate structure and the new species formed from the cis-3 in $\mathrm{CD}_{3} \mathrm{CN}$ may possess a meso structure.

\section{Conclusions}

30 In summary, we have successfully synthesised the photoresponsive spiroborate-based double-stranded helicate (cis3) bearing $c i s$-stilbene units in the middle, which underwent an extension $\left(c i s-\mathbf{3}_{\mathbf{E}}\right)$ and contraction $\left(c i s-\mathbf{3}_{\mathbf{C}}\right)$ motion by the $\mathrm{Na}^{+}$ion release and binding. Although photo-induced cis/trans ${ }_{35}$ isomerisation of cis-3 did not efficiently nor reversibly take place because of its highly strained spiroborated duplex structure in addition to the oxidative photo-cleavage of the trans-stilbene moieties under irradiation of UV light, the present results provide further design strategy for developing novel photoresponsive 40 spiroborate-based helicates that exhibit light-triggered spring-like motions by introducing an overcrowded double bond into the helicates as a photo- and thermo-responsive linker. ${ }^{2 \mathrm{a}, 2 \mathrm{c}, 2 \mathrm{~g}, 3}$

\section{Experimental section}

\section{Materials and instruments}

45 Materials. All starting materials and dehydrated solvents were purchased from commercial suppliers and were used without further purification unless otherwise noted. Silica gel $\left(\mathrm{SiO}_{2}\right)$ for the flash chromatography was purchased from Merck. The boronic acid (5), ${ }^{18}(E)-4,4^{\prime}$-diiodoazobenzene (6), ${ }^{19}$ the boronic ${ }_{50}$ acid pinacol ester (9), ${ }^{9}$ and $(Z)-4,4^{\prime}$-diiodostilbene $(\mathbf{1 0})^{20}$ were prepared according to the literature.

Instruments. The melting points were measured on an MPA100 OptiMelt automated melting point apparatus or a Yanaco MP-500D melting point apparatus (Kyoto, Japan), and 55 were uncorrected. The NMR spectra were obtained using a Varian UNITY INOVA 500AS spectrometer operating at 500 $\mathrm{MHz}$ for ${ }^{1} \mathrm{H}$ and $125 \mathrm{MHz}$ for ${ }^{13} \mathrm{C}$ or a Varian INOVA 700 spectrometer operating at $700 \mathrm{MHz}$ for ${ }^{1} \mathrm{H}$ and $175 \mathrm{MHz}$ for ${ }^{13} \mathrm{C}$ using tetramethysilane (TMS) or a solvent residual peak as the 60 internal standard. The electron spray ionization (ESI) mass spectra were recorded using a JEOL JMS-T100CS spectrometer (Akishima, Japan). The absorption spectra were measured in a 1or 10-mm quartz cell on a JASCO V-570 spectrophotometer. The photoirradiation for cis/trans isomerisation was performed on a ${ }_{65}$ JASCO FP-6500 spectrofluorometer with a $150 \mathrm{~W}$ xenon lamp under argon unless otherwise noted. The slit width used in the experiments was $20 \mathrm{~nm}$. The chiral HPLC analyses were performed on a JASCO PU-2080 liquid chromatograph equipped with UV-visible (JASCO MD-2010) and CD detectors (JASCO 70 CD-2095) using a Chiralpak IB column (0.46 (i.d.) x $25 \mathrm{~cm}$, Daicel, Osaka, Japan).

\section{Synthetic procedures}

trans-7. To a mixture of 5 (427 mg, $1.15 \mathrm{mmol})$, trans-6 (200 $\mathrm{mg}, 0.461 \mathrm{mmol})$, and $\mathrm{Pd}\left(\mathrm{PPh}_{3}\right)_{4}(133 \mathrm{mg}, 0.115 \mathrm{mmol})$ in 75 toluene $(7.2 \mathrm{~mL})$ was added $2 \mathrm{M}$ aqueous $\mathrm{K}_{2} \mathrm{CO}_{3}(7.2 \mathrm{~mL})$. The reaction mixture was stirred at $110{ }^{\circ} \mathrm{C}$ for $36 \mathrm{~h}$ under nitrogen. After being cooled to room temperature, the mixture was extracted with EtOAc. The organic layer was washed with $\mathrm{H}_{2} \mathrm{O}$ and dried over anhydrous $\mathrm{MgSO}_{4}$. After filtration, the solvent 80 was evaporated under reduced pressure. The crude product was purified by flash chromatography $\left(\mathrm{SiO}_{2}, 12 \mathrm{~g}\right)$ with $n$ hexane/EtOAc (10/0 to $10 / 1(\mathrm{v} / \mathrm{v}))$ to afford trans $-7(289 \mathrm{mg}$, $75.5 \%$ yield) as an orange solid. Mp: $275.1-276.0^{\circ} \mathrm{C} .{ }^{1} \mathrm{H}$ NMR (500 MHz, $\mathrm{CDCl}_{3}$, r.t.): $\delta 8.00$ (d, $\left.J=8.5 \mathrm{~Hz}, 4 \mathrm{H}, \mathrm{ArH}\right), 7.80$ (d,

85<smiles>COc1ccc(C(C)(C)C)cc1-c1cc(Br)cc(Br)c1OC</smiles>

5<smiles>Ic1ccc(N=Nc2ccc(I)cc2)cc1</smiles>

trans-6

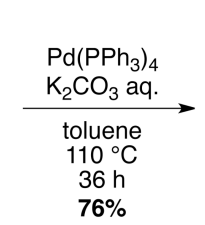<smiles>COc1ccc(Br)cc1-c1cc(Br)cc(-c2ccc(N)cc2)c1OC</smiles>

trans-7

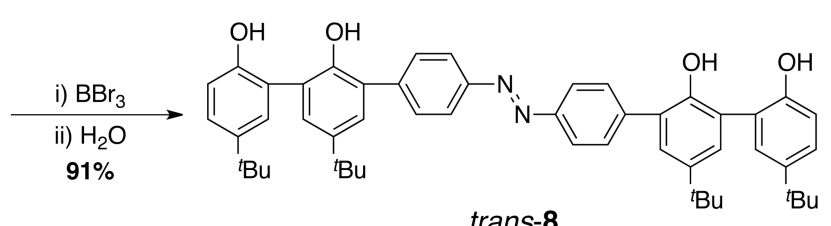

trans-8

Scheme 4 Synthesis of trans-azobenzene ligand (trans-8). 

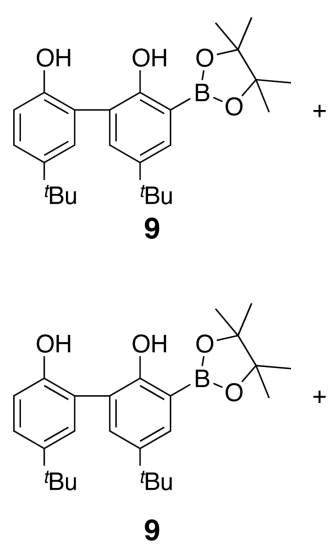

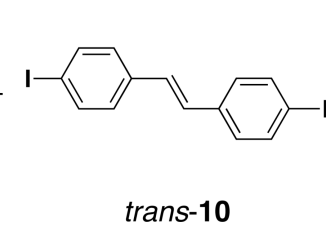

trans-10

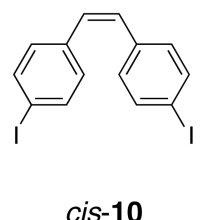

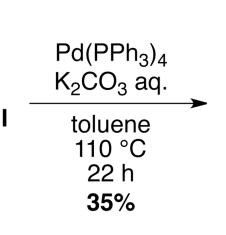

$\mathrm{Pd}\left(\mathrm{PPh}_{3}\right)_{4}$

$\underset{\mathrm{K}_{2} \mathrm{CO}_{3} \text { aq. }}{\longrightarrow}$
toluene
$105^{\circ} \mathrm{C}$
$29 \mathrm{~h}$
$45 \%$

Scheme 5 Synthesis of stilbene ligands (trans-11 and cis-11).

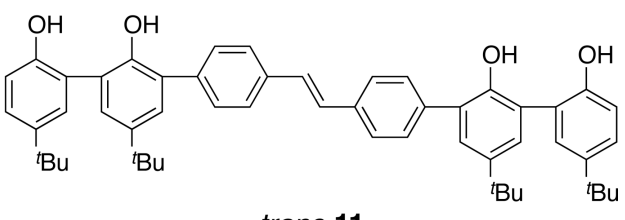

trans-11

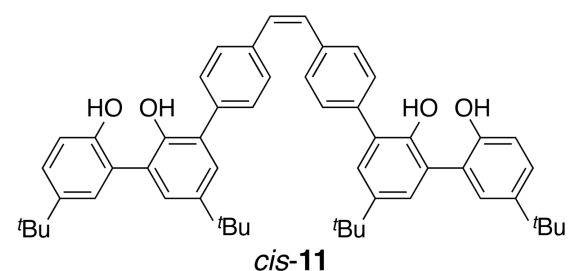

$J=8.5 \mathrm{~Hz}, 4 \mathrm{H}, \mathrm{ArH}), 7.40-7.36(\mathrm{~m}, 8 \mathrm{H}, \mathrm{ArH}), 6.95(\mathrm{~d}, J=8.5$ $\left.{ }_{5} \mathrm{~Hz}, 2 \mathrm{H}, \mathrm{ArH}\right), 3.81\left(\mathrm{~s}, 6 \mathrm{H}, \mathrm{OCH}_{3}\right), 3.24\left(\mathrm{~s}, 6 \mathrm{H}, \mathrm{OCH}_{3}\right), 1.38$ (s, $\left.18 \mathrm{H}, \mathrm{C}\left(\mathrm{CH}_{3}\right)_{3}\right), 1.34\left(\mathrm{~s}, 18 \mathrm{H}, \mathrm{C}\left(\mathrm{CH}_{3}\right)_{3}\right) .{ }^{13} \mathrm{C} \mathrm{NMR}(125 \mathrm{MHz}$, $\mathrm{CDCl}_{3}$, r.t.): $\delta 154.79,153.46,151,78,146.06,143.12,142.62$, 133.36, 132.33, 130.25, 129.30, 129.05, 127.61, 127.34, 125.32, $122.86,110.69,60.73,55.90,34.64,34.30,31.74,31.68$. HRMS 10 (positive mode ESI): $\mathrm{m} / \mathrm{z}$ calcd for $\left[\mathrm{M}\left(\mathrm{C}_{56} \mathrm{H}_{66} \mathrm{~N}_{2} \mathrm{O}_{4}\right)+\mathrm{Na}^{+}\right]^{+}$, 853.4920; found 853.4922 .

trans-8. To a solution of trans $-7(200 \mathrm{mg}, 0.241 \mathrm{mmol})$ in $\mathrm{CH}_{2} \mathrm{Cl}_{2}(5.0 \mathrm{~mL})$ was added a $\mathrm{CH}_{2} \mathrm{Cl}_{2}$ solution of $\mathrm{BBr}_{3}(1.0 \mathrm{M}$, $2.41 \mathrm{~mL}, 2.41 \mathrm{mmol})$ at $-78{ }^{\circ} \mathrm{C}$ under nitrogen. After being 15 warmed to room temperature, the reaction mixture was stirred for 19 h. The mixture was then quenched with $\mathrm{H}_{2} \mathrm{O}(10 \mathrm{~mL})$ at $0{ }^{\circ} \mathrm{C}$ and stirred at room temperature for $1 \mathrm{~h}$. After the solvent was evaporated, the residue was extracted with EtOAc. The organic layer was washed with $\mathrm{H}_{2} \mathrm{O}$ and dried over anhydrous $\mathrm{MgSO}_{4}$.

20 After filtration, the solvent was evaporated under reduced chromatography with $n$-hexane/EtOAc (10/0 to $10 / 1(\mathrm{v} / \mathrm{v}))$ to afford trans $\mathbf{8} \mathbf{8}(170 \mathrm{mg}, 90.9 \%$ yield $)$ as a dark orange solid. Mp: 156.5-158.1 ${ }^{\circ} \mathrm{C}(\mathrm{dec}) .{ }^{1} \mathrm{H}$ NMR $\left(500 \mathrm{MHz}, \mathrm{CDCl}_{3}\right.$, r.t.): $\delta 8.06$ $(\mathrm{d}, J=8.5 \mathrm{~Hz}, 4 \mathrm{H}, \mathrm{ArH}), 7.77$ (d, $J=8.5 \mathrm{~Hz}, 4 \mathrm{H}, \mathrm{ArH}), 7.44$ (d, $J$ $\left.{ }_{25}=2.5 \mathrm{~Hz}, 2 \mathrm{H}, \mathrm{ArH}\right), 7.38(\mathrm{dd}, J=2.5,8.5 \mathrm{~Hz}, 2 \mathrm{H}, \mathrm{ArH}), 7.33(\mathrm{~m}$, $4 \mathrm{H}, \mathrm{ArH}), 7.01$ (d, $J=8.5 \mathrm{~Hz}, 2 \mathrm{H}, \mathrm{ArH}), 5.55$ (s, 2H, ArOH), $5.47(\mathrm{~s}, 2 \mathrm{H}, \mathrm{ArOH}), 1.39\left(\mathrm{~s}, 18 \mathrm{H}, \mathrm{C}\left(\mathrm{CH}_{3}\right)_{3}\right), 1.35(\mathrm{~s}, 18 \mathrm{H}$, $\left.\mathrm{C}\left(\mathrm{CH}_{3}\right)_{3}\right) .{ }^{13} \mathrm{C} \mathrm{NMR}\left(125 \mathrm{MHz}, \mathrm{CDCl}_{3}\right.$, r.t.): $\delta 152.03,151.13$, $147.67,144.58,144.49,141.02,130.35,128.38,128.15,128.08$, $30128.00,127.23,124.26,123.42,123.41,116.56,34.55,34.43$, 31.71 (19 signals out of 20 expected ones). HRMS (negative mode ESI): $\mathrm{m} / \mathrm{z}$ calcd for $\left[\mathrm{M}\left(\mathrm{C}_{52} \mathrm{H}_{58} \mathrm{~N}_{2} \mathrm{O}_{4}\right)-\mathrm{H}^{+}\right]^{-}, 773.4318$; found 773.4311 .

trans-11. To a solution of 9 ( $93 \mathrm{mg}, 0.22 \mathrm{mmol})$, trans $-\mathbf{1 0}$ (43 $35 \mathrm{mg}, 0.10 \mathrm{mmol})$, and $\mathrm{Pd}\left(\mathrm{PPh}_{3}\right)_{4}(23 \mathrm{mg}, 0.020 \mathrm{mmol})$ in toluene $(5.0 \mathrm{~mL})$ was added $2 \mathrm{M}$ aqueous $\mathrm{K}_{2} \mathrm{CO}_{3}(5.0 \mathrm{~mL})$. The reaction mixture was stirred at $110^{\circ} \mathrm{C}$ for $22 \mathrm{~h}$ under nitrogen. After being cooled to room temperature, the mixture was extracted with EtOAc. The organic layer was washed with $\mathrm{H}_{2} \mathrm{O}$ and aqueous ${ }_{40} \mathrm{HCl}$, and dried over anhydrous $\mathrm{MgSO}_{4}$. After filtration, the solvent was evaporated under reduced pressure. The crude product was purified by flash chromatography $\left(\mathrm{SiO}_{2}, 12 \mathrm{~g}\right)$ with $n$-hexane/EtOAc $(10 / 0$ to $6 / 4(\mathrm{v} / \mathrm{v}))$ to afford trans-11 $(27 \mathrm{mg}$, $35 \%$ yield) as a white solid. $\varepsilon_{298}: 2.73 \times 10^{5} \mathrm{M}^{-1} \mathrm{~cm}^{-1}$. Mp: 152.8 45 $155.6{ }^{\circ} \mathrm{C}$. ${ }^{1} \mathrm{H}$ NMR $\left(500 \mathrm{MHz}, \mathrm{CDCl}_{3}\right.$, r.t.) $\delta 7.67$ (d, $J=8.5 \mathrm{~Hz}$,
4H, ArH), 7.59 (d, $J=8.5 \mathrm{~Hz}, 4 \mathrm{H}, \mathrm{ArH}), 7.39$ (d, $J=2.5 \mathrm{~Hz}, 2 \mathrm{H}$, ArH), 7.37 (dd, $J=2.5,8.5 \mathrm{~Hz}, 2 \mathrm{H}, \mathrm{ArH}), 7.33(\mathrm{~d}, J=2.5 \mathrm{~Hz}$, $2 \mathrm{H}, \mathrm{ArH}), 7.31(\mathrm{~d}, J=2.5 \mathrm{~Hz}, 2 \mathrm{H}, \mathrm{ArH}), 7.23(\mathrm{~s}, 2 \mathrm{H}, \mathrm{HC}=\mathrm{CH})$, $7.01(\mathrm{~d}, J=8.5 \mathrm{~Hz}, 4 \mathrm{H}, \mathrm{ArH}), 5.56(\mathrm{~s}, 2 \mathrm{H}, \mathrm{OH}), 5.52(\mathrm{~s}, 2 \mathrm{H}$, $\left.{ }_{50} \mathrm{OH}\right), 1.37\left(\mathrm{~s}, 18 \mathrm{H}, \mathrm{C}\left(\mathrm{CH}_{3}\right)_{3}\right), 1.34\left(\mathrm{~s}, 18 \mathrm{H}, \mathrm{C}\left(\mathrm{CH}_{3}\right)_{3}\right) .{ }^{13} \mathrm{C} \mathrm{NMR}$ (125 MHz, $\mathrm{CDCl}_{3}$, r.t.): $\delta$ 151.23, 147.34, 144.54, 144.32, $137.24,136.89,129.86,128.72,128.36,128.15,127.81,127.20$, $127.05,124.20,123.91,116.67,34.53,34.41,31.72,31.71(20$ signals out of 21 expected ones). HRMS(ESI): $\mathrm{m} / \mathrm{z}$ calcd for ${ }_{55}\left[\mathrm{M}\left(\mathrm{C}_{54} \mathrm{H}_{60} \mathrm{O}_{4}\right)-\mathrm{H}^{+}\right]^{-}, 771.4413$; found 771.4379.

cis-11. To a solution of 9 (216 mg, $0.509 \mathrm{mmol})$, cis-10 (100 $\mathrm{mg}, 0.231 \mathrm{mmol})$, and $\mathrm{Pd}\left(\mathrm{PPh}_{3}\right)_{4}(58.8 \mathrm{mg}, 0.0509 \mathrm{mmol})$ in toluene $(5.0 \mathrm{~mL})$ was added $2 \mathrm{M}$ aqueous $\mathrm{K}_{2} \mathrm{CO}_{3}(5.0 \mathrm{~mL})$. The reaction mixture was stirred at $105{ }^{\circ} \mathrm{C}$ for $29 \mathrm{~h}$ under nitrogen. ${ }_{60}$ After being cooled to room temperature, the mixture was extracted with EtOAc. The organic layer was washed with $\mathrm{H}_{2} \mathrm{O}$ and dried over anhydride $\mathrm{MgSO}_{4}$. After filtration, the solvent was evaporated under reduced pressure. The crude product was purified by flash chromatography $\left(\mathrm{SiO}_{2}, 12 \mathrm{~g}\right)$ with $n$ ${ }_{65}$ hexane/EtOAc $(10 / 0$ to $8 / 2(\mathrm{v} / \mathrm{v}))$ to afford cis-11 $(80.0 \mathrm{mg}$, $44.7 \%$ yield) as a white solid. $\varepsilon_{298}: 2.73 \times 10^{5} \mathrm{M}^{-1} \mathrm{~cm}^{-1} . \mathrm{Mp}$ : $136.5-138.9^{\circ} \mathrm{C} .{ }^{1} \mathrm{H} \mathrm{NMR}\left(500 \mathrm{MHz}, \mathrm{CDCl}_{3}\right.$, r.t.) $\delta 7.48-7.45$ (m, $8 \mathrm{H}, \mathrm{ArH}), 7.36(\mathrm{~d}, J=2.5 \mathrm{~Hz}, 2 \mathrm{H}, \mathrm{ArH}), 7.35(\mathrm{dd}, J=2.5,8.5$ $\mathrm{Hz}, 2 \mathrm{H}, \mathrm{ArH}), 7.31$ (d, $J=2.4 \mathrm{~Hz}, 2 \mathrm{H}, \mathrm{ArH}), 7.29$ (d, $J=2.5 \mathrm{~Hz}$, $702 \mathrm{H}, \mathrm{ArH}), 6.99(\mathrm{~d}, J=8.5 \mathrm{~Hz}, 2 \mathrm{H}, \mathrm{ArH}), 6.68(\mathrm{~s}, 2 \mathrm{H}, \mathrm{HC}=\mathrm{CH})$, $5.57(\mathrm{~s}, 2 \mathrm{H}, \mathrm{OH}), 5.54(\mathrm{~s}, 2 \mathrm{H}, \mathrm{OH}), 1.35\left(\mathrm{~s}, 18 \mathrm{H}, \mathrm{C}\left(\mathrm{CH}_{3}\right)_{3}\right), 1.33$ (s, $\left.18 \mathrm{H}, \mathrm{C}\left(\mathrm{CH}_{3}\right)_{3}\right) \cdot{ }^{13} \mathrm{C}$ NMR $\left(125 \mathrm{MHz}, \mathrm{CDCl}_{3}\right.$, r.t.): $\delta 151.22$, $147.28,144.49,144.26,136.74,136.73,130.27,129.59,129.38$, $128.30,128.13,128.11,127.80,127.00,124.14,123.93,116.62$, $7534.51,34.39,31.71,31.70$. HRMS(ESI): $\mathrm{m} / \mathrm{z}$ calcd for $\left[\mathrm{M}\left(\mathrm{C}_{54} \mathrm{H}_{60} \mathrm{O}_{4}\right)-\mathrm{H}^{+}\right]^{-}, 771.4413$; found 771.4380.

trans-2. To a solution of trans $\mathbf{8}(3.0 \mathrm{mg}, 3.9 \mu \mathrm{mol})$ in $1,2-$ dichloroethane $(625 \mu \mathrm{L})$ was added a solution of $\mathrm{NaBH}_{4}$ in ethanol $(31.2 \mathrm{mM}, 125 \mu \mathrm{L}, 3.90 \mu \mathrm{mol})$. The reaction mixture was 30 stirred at $80^{\circ} \mathrm{C}$ for $20 \mathrm{~h}$ under argon. After being cooled to room temperature, the solvents were evaporated under reduced pressure and the residue was dried in vacco. The negative ESI mass spectrum of the residue dissolved in $\mathrm{CD}_{3} \mathrm{CN}$ was then measured using $\mathrm{CH}_{3} \mathrm{CN}$ as the eluent (Fig. $\mathrm{S} 1$ in ESI $\dagger$ ).

85 trans-3. To a solution of trans-11 $(3.3 \mathrm{mg}, 4.3 \mu \mathrm{mol})$ in 1,2dichloroethane $(486 \mu \mathrm{L})$ was added a solution of $\mathrm{NaBH}_{4}$ in ethanol $(44.0 \mathrm{mM}, 98 \mu \mathrm{L}, 4.3 \mu \mathrm{mol})$. The reaction mixture was 
stirred at $80{ }^{\circ} \mathrm{C}$ for $20 \mathrm{~h}$ under argon, resulting in a precipitate. After being cooled to room temperature, the solvents were evaporated under reduced pressure and the residue was dried in vacco. The negative ESI mass spectrum was measured after the 5 residue was dissolved in DMSO- $d_{6}$ and then diluted with $\mathrm{CH}_{3} \mathrm{CN}$ (Fig. S2 in ESI†े).

cis-3. To a solution of cis-11 $(20.5 \mathrm{mg}, 26.5 \mu \mathrm{mol})$ in 1,2dichloroethane $(3.0 \mathrm{~mL})$ was added a solution of $\mathrm{NaBH}_{4}$ in ethanol $(44.5 \mathrm{mM}, 0.60 \mathrm{~mL}, 27 \mu \mathrm{mol})$. The reaction mixture was 10 stirred at $80{ }^{\circ} \mathrm{C}$ for $20 \mathrm{~h}$ under argon. The precipitate obtained from the mixture during the reaction was collected by filtration, washed with 1,2-dichloroethane, and dried in vacco to afford cis3 as a white solid in $51.6 \%$ yield $(11.0 \mathrm{mg}) . \mathrm{Mp}:>300{ }^{\circ} \mathrm{C} .{ }^{1} \mathrm{H}$ NMR $\left(500 \mathrm{MHz}, \mathrm{DMSO}-d_{6}, 25^{\circ} \mathrm{C}\right) \delta 7.33(\mathrm{~d}, J=8.5 \mathrm{~Hz}, 8 \mathrm{H}$, $\left.{ }_{15} \mathrm{ArH}\right), 7.19$ (d, $\left.J=2.0 \mathrm{~Hz}, 4 \mathrm{H}, \mathrm{ArH}\right), 7.18$ (d, $J=2.5 \mathrm{~Hz}, 4 \mathrm{H}$, ArH), 7.09 (dd, $J=2.5,8.5 \mathrm{~Hz}, 4 \mathrm{H}, \operatorname{ArH}), 7.06(\mathrm{~d}, J=2.5 \mathrm{~Hz}$, $4 \mathrm{H}, \mathrm{ArH}), 6.79$ (d, $J=8.5 \mathrm{~Hz}, 8 \mathrm{H}, \mathrm{ArH}), 6.56$ (d, $J=8.5 \mathrm{~Hz}, 4 \mathrm{H}$, $\mathrm{ArH}), 6.27(\mathrm{~s}, 4 \mathrm{H}, \mathrm{CH}=\mathrm{CH}), 1.30\left(\mathrm{~s}, 36 \mathrm{H}, \mathrm{C}\left(\mathrm{CH}_{3}\right)_{3}\right), 1.25(\mathrm{~s}$, $\left.36 \mathrm{H}, \mathrm{C}\left(\mathrm{CH}_{3}\right)_{3}\right) .{ }^{13} \mathrm{C}$ NMR $\left(175 \mathrm{MHz}\right.$, DMSO- $\left.d_{6}, 40{ }^{\circ} \mathrm{C}\right): \delta$ $20154.90,152.16,140.82,140.38,139.23,133.79,131.23,130.86$, $130.78,129.00,126.92,125.54,124.93,124.34,124.80,120.67$, $33.57,33.52,31.47,31.34$ (20 signals out of 21 expected ones). HRMS(ESI): $\mathrm{m} / \mathrm{z}$ calcd for $\left[\mathrm{M}\left(\mathrm{C}_{108} \mathrm{H}_{112} \mathrm{~B}_{2} \mathrm{Na}_{2} \mathrm{O}_{8}\right)-\mathrm{Na}^{+}\right]^{-}$, 1581.8470; found 1581.8462 .

\section{${ }_{25}$ 3. Computational calculations}

We used quantum chemical approaches, as implemented in the Gaussian 09 package, ${ }^{21}$ to construct model double-stranded spiroborate helicates. Geometry optimisations were performed at different levels of theory, namely Hartree-Fock (HF) and density 30 functional theory (DFT) using the hybrid $\omega$ B97X-D functional, ${ }^{22}$ for dianions, monoanions and neutral helicates. For all optimised geometries, a subsequent frequency calculation was performed to verify that geometries correspond to energy minimums. The effect of basis set on geometries and properties was checked by 35 increasing the basis set from the standard $3-21 \mathrm{G}$ basis up to the 6$31 \mathrm{G}^{*}$. Calculations were conducted both in vacuum and in the presence of solvent $\left(\mathrm{CH}_{3} \mathrm{CN}\right)$ using the Polarizable Continuum Model (PCM) as implemented in Gaussian 09.

For several helicates, we have first verified at the $\mathrm{HF} / 3-21 \mathrm{G}$ 40 level of theory in vacuum that substitution of the ${ }^{t} \mathrm{Bu}$ groups with hydrogen atoms does not significantly change the optimized geometries and respective stability of the structures. For these simplified structures, we were able to increase the basis set up to 6-31G* and at the same time afford frequency calculations for 45 solvated structures. In fact, relying solely on differences of electronic energies or on geometries optimized in vacuum appears to be insufficient to properly describe the relative stability of such double-stranded spiroborate helicates. In addition, geometry optimization was found to be more involved 50 with the $\omega$ B97X-D functional than at the HF level but leads to consistent results whenever available. We thus retained the HF/6$31 \mathrm{G}^{*}$ level of theory in $\mathrm{CH}_{3} \mathrm{CN}$ and summarize the main results in Table S1. Comparison of the monoanion cis-3 $\mathbf{3}_{\mathbf{C}}$ with the dianion cis $-\mathbf{3}_{\mathbf{E}}$ and a free sodium cation needs to be corrected for 55 basis set superposition errors (BSSE). This could be qualitatively estimated from electronic energies in vacuum where BSSE amounts to $c a .3 \mathrm{kcal} \mathrm{mol}^{-1}$.

\section{Acknowledgements}

This work was supported in part by Grant-in-Aids for Scientific ${ }_{60}$ Research (S) from the JSPS (E.Y.) and by Program for Leading Graduate Schools "Integrative Graduate Education and Research in Green Natural Sciences", MEXT, Japan. C.K. acknowledges the HPC resources of CINES and of IDRIS under the allocations 2013-[x2013080649] made by GENCI (Grand Equipement ${ }_{65}$ National de Calcul Intensif) for generous support of this work. The authors are grateful to Dr. Kazuhiro Miwa (Nagoya University) and Prof. Yoshio Furusho (Kinki University) for their help in the synthesis of trans-8.

\section{Notes and references}

701 For recent reviews on molecular machines including molecular motors and artificial muscles using external stimuli, see: (a) V. Balzani, A. Credi, F. M. Raymo and J. F. Stoddart, Angew. Chem., Int. Ed., 2000, 39, 3348-3391; (b) J.-P. Collin, C. DietrichBuchecker, P. Gavina, M. C. Jimenez-Molero and J.-P. Sauvage, Acc. Chem. Res., 2001, 34, 477-487; (c) C. A. Schalley, K. Beizai and F. Vögtle, Acc. Chem. Res., 2001, 34, 465-476; (d) G. S. Kottas, L. L. Clarke, D. Horinek and J. Michl, Chem. Rev., 2005, 105, 1281-1376; (e) K. Kinbara and T. Aida, Chem. Rev., 2005, 105, 1377-1400; (f) V. Balzani, A. Credi, S. Silvi and M. Venturi, Chem. Soc. Rev., 2006, 35, 1135-1149; (g) E. R. Kay, D. A. Leigh and F. Zerbetto, Angew. Chem., Int. Ed., 2007, 46, 72-92; (h) V. Balzani, A. Credi and M. Venturi, Molecular Devices and Machines: Concepts and Perspectives for the Nanoworld, 2nd Ed., Wiley-VCH, Weinheim, 2008; (i) F. Niess, V. Duplan and J.-P. Sauvage, Chem. Lett., 2014,

85 43, 964-974; (j) C. J. Bruns and J. F. Stoddart, Acc. Chem. Res., 2014, 47, 2186-2199.

2 For reviews on photoresponsive molecular machines, see: (a) B. L. Feringa, R. A. van Delden, N. Koumura and E. M. Geertsema, Chem. Rev., 2000, 100, 1789-1816; (b) Molecular Switches, ed., B. L. 90 Feringa, Wiley-VCH, Weinheim, 2001; (c) B. L. Feringa, Acc. Chem. Res., 2001, 34, 504-513; (d) S. Saha and J. F. Stoddart, Chem. Soc. Rev., 2007, 36, 77-92; (e) M.-M. Russew and S. Hecht, Adv. Mater., 2010, 22, 3348-3360; (f) F. D. Jochum and P. Theato, Chem. Soc. Rev., 2013, 42, 7468-7483. (g) C. García-Iriepa, M. Marazzi, L. M. Frutos and D. Sampedro, RSC Adv., 2013, 3, 6241-6266.

3 For leading references on photoresponsive molecular motors based on photoswitchable overcrowded $\mathrm{C}=\mathrm{C}$ bonds, see: $(a) \mathrm{N}$. Koumura, R. W. J. Zijlstra, R. A. van Delden, N. Harada and B. L. Feringa, Nature, 1999, 401, 152-155; (b) R. A. van Delden, M. K. J. ter Wiel, M. M. Pollard, J. Vicario, N. Koumura and B. L. Feringa, Nature, 2005, 437, 1337-1340; (c) R. Eelkema, M. M. Pollard, J. Vicario, N. Katsonis, B. S. Ramon, C. W. M. Bastiaansen, D. J. Broer and B. L. Feringa, Nature, 2006, 440, 163.

4 For photoresponsive doubly threaded rotaxanes, see: (a) S. Tsuda, Y. Aso and T. Kaneda, Chem. Commun., 2006, 3072-3074; (b) R. E. Dawson, S. F. Lincoln and C. J. Easton, Chem. Commun., 2008, 3980-3982; (c) S. Li, D. Taura, A. Hashidzume, A. Harada, Chem. Eur. J., 2010, 5, 2281-2289; For a photoresponsive double helix, see: (d) Y. Furusho, Y. Tanaka, T. Maeda, M. Ikeda and E. Yashima, Chem. Commun., 2007, 3174-3176.

5 For reviews on photoresponsive systems for molecular devices and functional materials, see: (a) M. Irie, Adv. Polym. Sci., 1990, 94, 2767; (b) S. Kawata and Y. Kawata, Chem. Rev., 2000, 100, 17771788; (c) A. Natansohn and P. Rochon, Chem. Rev., 2002, 102, 4139-4175; (d) R. Klajn, J. F. Stoddart and B. A. Grzybowski, Chem. Soc. Rev., 2010, 39, 2203-2237; (e) R. S. Stoll and S. Hecht, Angew. Chem., Int. Ed., 2010, 49, 5054-5075.

6 H. Katagiri, T. Miyagawa, Y. Furusho and E. Yashima, Angew. Chem., Int. Ed., 2006, 45, 1741-1744.

1207 (a) K. Miwa, Y. Furusho and E. Yashima, Nature Chem., 2010, 2, 444-449; (b) K. Miwa, K. Shimizu, H. Min, Y. Furusho and E. Yashima, Tetrahedron, 2012, 68, 4470-4478. 
8 Y. Furusho, K. Miwa, R. Asai and E. Yashima, Chem. Eur. J., 2011, 17, 13954-13957.

9 S. Yamamoto, H. Iida and E. Yashima, Angew. Chem., Int. Ed., 2013, 52, 6849-6853.

510 For examples of photoresponsive supramolecular systems using stilbene residues, see: (a) C. A. Stanier, S. J. Alderman, T. D. W. Claridge and H. L. Anderson, Angew. Chem., Int. Ed., 2002, 41, 1769-1772; (b) D.-H. Qu, Q.-C. Wang and H. Tian, Angew. Chem., Int. Ed., 2005, 44, 5296-5299; (c) P. Kuad, A. Miyawaki, Y.

10 Takashima, H. Yamaguchi and A. Harada, J. Am. Chem. Soc., 2007 129, 12630-12631; (d) V. Serreli, C.-F. Lee, E. R. Kay and D. A. Leigh, Nature, 2007, 445, 523-527.

11 For examples of photoresponsive supramolecular systems using azobenzene residues, see: (a) S. Shinkai, T. Nakaji, T. Ogawa, K. Shigematsu and O. Manabe, J. Am. Chem. Soc., 1981, 103, 111-115; (b) H. Murakami, A. Kawabuchi, K. Kotoo, M. Kunitake and N. Nakashima, J. Am. Chem. Soc., 1997, 119, 7605-7606; (c) T. Muraoka, K. Kinbara, T. Aida, Nature, 2006, 440, 512-515.

12 For reviews on photoresponsive synthetic polymers, polypeptides, polynucleotides, and foldamers with a single-stranded helical conformation, see: (a) O. Pieroni, A. Fissi and G. Popova, Prog. Polym. Sci., 1998, 23, 81-123; (b) E. Yashima in Chiral Photochemistry, ed. Y. Inoue and V. Ramamurthy, Marcel Dekker, New York, 2004, pp. 633-665; (c) E. Yashima, K. Maeda, H. Iida, Y. 25 Furusho and K. Nagai, Chem. Rev., 2009, 109, 6102-6211; (d) Y. Kamiya and H. Asanuma, Acc. Chem. Res., 2014, 47, 1663-1672.

13 For examples of photoresponsive helical foldamers, see: (a) A. Khan, C. Kaiser and S. Hecht, Angew. Chem., Int. Ed., 2006, 45, 18781881; (b) C. Tie, J. C. Gallucci and J. R. Parquette, J. Am. Chem.

$30 \quad$ Soc., 2006, 128, 1162-1171; (c) A. Khan and S. Hecht, Chem. Eur J., 2006, 12, 4764-4774; (d) Y. Hua and A. H. Flood, J. Am. Chem. Soc., 2010, 132, 12838-12840; (e) H. Sogawa, M. Shiotsuki, H. Matsuoka and F. Sanda, Macromolecules, 2011, 44, 3338-3345; (f) Z. Yu, S. Weidner, T. Risse and S. Hecht, Chem. Sci., 2013, 4, 41564167.

14 (a) C. L. Perrin and T. J. Dwyer, Chem. Rev., 1990, 90, 935-967; (b) M. Pons and O. Millet, Prog. Nucl. Magn. Reson. Spectrosc., 2001,
38, 267-324; (c) N. Nishimura, K. Yoza and K. Kobayashi, J. Am. Chem. Soc., 2010, 132, 777-790.

4015 (a) D. H. Waldeck, Chem. Rev., 1991, 91, 415-436; (b) T. Arai and K. Tokumaru, Chem. Rev., 1993, 93, 23-39.

16 Calculation results suggest that relative Gibbs free energy between cis $-\mathbf{3}_{\mathbf{E}}$ and trans $-\mathbf{3}_{\mathbf{E}}$ is not significantly different (Table $\mathrm{S} 1$ in ESI $\dagger$ ).

17 For photooxidation of stilbene derivatives resulting in the formation of aldehydes, see: (a) H. Maeda, K.-i. Nishimura, K. Mizuno, M. Yamaji, J. Oshima and S. Tobita, J. Org. Chem., 2005, 70, 9693 9701, and references therein; (b) M. A. Fourati, W. G. Skene, C. G. Bazuin and R. E. Prud'homme, J. Phys. Chem. A, 2013, 117, 836844

5018 C. Kabuto, S. Akine, T. Nemoto, E. Kwon, J. Cryst. Soc. Jpn., 2009, 51, 218-224.

19 D. Grebel-Koehler, D. Liu, S. De Feyter, V. Enkelmann, T. Weil, C. Engels, C. Samyn, K. Müllen, F. C. De Schryver, Macromolecules, 2003, 36, 578-590.

5520 F. Babudri, A. Cardone, T. Cassano, G. M. Farinola, F. Naso, R. Tommasi, J. Organomet. Chem., 2008, 693, 2631-2636.

21 M. J. Frisch, G. W. Trucks, H. B. Schlegel, G. E. Scuseria, M. A. Robb, J. R. Cheeseman, G. Scalmani, V. Barone, B. Mennucci, G. A. Petersson, H. Nakatsuji, M. Caricato, X. Li, H. P. Hratchian, A. F. 60 Izmaylov, J. Bloino, G. Zheng, J. L. Sonnenberg, M. Hada, M. Ehara K. Toyota, R. Fukuda, J. Hasegawa, M. Ishida, T. Nakajima, Y. Honda, O. Kitao, H. Nakai, T. Vreven, J. A. Montgomery, Jr., J. E. Peralta, F. Ogliaro, M. Bearpark, J. J. Heyd, E. Brothers, K. N. Kudin, V. N. Staroverov, R. Kobayashi, J. Normand, K. 65 Raghavachari, A. Rendell, J. C. Burant, S. S. Iyengar, J. Tomasi, M. Cossi, N. Rega, J. M. Millam, M. Klene, J. E. Knox, J. B. Cross, V. Bakken, C. Adamo, J. Jaramillo, R. Gomperts, R. E. Stratmann, O. Yazyev, A. J. Austin, R. Cammi, C. Pomelli, J. W. Ochterski, R. L. Martin, K. Morokuma, V. G. Zakrzewski, G. A. Voth, P. Salvador, J.

70 J. Dannenberg, S. Dapprich, A. D. Daniels, Ö. Farkas, J. B. Foresman, J. V. Ortiz, J. Cioslowski and D. J. Fox, Gaussian 09, Revision A.02, Gaussian, Inc., Wallingford CT, 2009.

22 J. D. Chai and M. Head-Gordon, Phys. Chem. Chem. Phys., 2008, 10, 6615-6620. 